\title{
Heat detection techniques in cattle and buffalo
}

\author{
Thakur Krishna Shankar Rao, Niranjan Kumar, Pankaj Kumar ${ }^{1}$, Shailendra Chaurasia and Navin B. Patel
}

Vanbandhu Veterinary College, Navsari Agricultural University, Navsari, Gujarat, India

1. Veterinary College, Sardar Krushinagar Dantiwada Agricultural University,

Sardar Krushinagar - 385506, Dantiwada, India

Corresponding author: Thakur Krishna Shankar Rao, email:tksrao.vet@gmail.com

Received: 02-11-2012, Accepted: 15-11-2012, Published online: 30-03-2013

How to cite this article:

Rao TKS, Kumar N, Kumar P, Chaurasia S and Patel NB (2013) Heat detection techniques in cattle and buffalo, Vet. World 6(6): 363-369, doi: 10.5455/vetworld.2013.363-369

\begin{abstract}
Proper heat detection to achieve appropriate timing of insemination is the biggest restriction in attaining high conception rate in dairy herd. The estrus detection is the key issue to be considered on priority basis. Inefficient heat detection reduces the fertility status of herd. Interventions in existing management practices manifest estrus nicely. Manifestation of estrus is due to effect of estrogen on Central Nervous System (CNS). The standing to be ridden is the best reliable sign of estrus. Ovulation time is well estimated by standing heat. Different factors are responsible which affect estrous behavior, out of which feeding and management interventions are one of the most important factor. For improving efficiency of heat detection in animal visual observation is best method, if it is done three times a day for at least 30 minutes every time, however heat detection aids, if used in combination give better results. The progesterone $\left(\mathrm{P}_{4}\right)$ estimation in milk and ultrasound monitoring of ovary and reproductive tracts for estimation of ovulation time are other important methods. Ovulation time is very important point in dairy reproduction management, as optimum time for Artificial Insemination (A.I.) is based on, when ovulation takes place. It is already established that, estrus detection alone contributes considerably to reproductive status of the herd, therefore the need of the our is critical observation of dairy herd to reduce incidence of unnoticed estrus.
\end{abstract}

Keywords: buffalo, cow, estrus, heat detection, ovulation

\section{I ntroduction}

The success of Artificial Insemination (A.I.) depends on critical observation of animals to detect heat at appropriate time as late insemination leads to failure of conception. Heat detection is the key in the success of an effective breeding program. This was achieved by close observation, timed A.I. and sound record keeping [1]. The performance of herd in general and female in particular depend on how female animals being noticed in heat and when they are offered A.I. Each missed heat is equivalent to 21 days loss in production. As heat detection is labour intensive and time consuming method, its success depends on the abilities, skill, approach and attitude of dairy farm labour. Incentive based additional working hrs may increase the chances of heat detection at appropriate time. Lacunae in the system of heat detection at any level ultimately create a loss to dairy farm [2]. The problem of heat detection is more prevalent in buffaloes. The situation more worsen due to delayed sexual maturity, post partum involution and silent estrus. The reproductive efficiency depends on, how soon after calving, the cow come into heat and success of first or subsequent insemination. The ultimate goal of heat detection is to predict actual time of ovulation.

\section{Estrus}

The term estrus was used for the first time by Heape [3]. The origin of word estrus is from a Latin

This article is an open access article licensed under the terms of the Creative Commons Attribution License (http://creativecommons. org/licenses/by/2.0) which permits unrestricted use, distribution and reproduction in any medium, provided the work is properly cited. adapted Greek word "Oistros", which means gad fly, sting, frenzy or rage to describe "period of sexual desire in female". In female cow the estrus behavior comprised of attractiveness, proceptivity and receptivity. Estrus is the period during reproductive cycle when female animals become sexually accessible. During estrus cow show clear cut behavioral signs especially firm footing and allowing herd mate to mount on her, the condition is known as "standing heat". The acceptance of the male by rage animal during estrum is due to the effect of estradiol on Central Nervous System [4]. Moreover it also prepares the uterus to receive a fertilized egg [5]. Estrogen found to reduce viscosity of cervical mucus, which leads to thin transparent discharge with fern pattern. Dilatation of cervix, improvement in contractility and tonicity observed on the day of estrus is due to rise in estrogen. The estrogen is produced by developing follicles of the ovary. In most of domestic animals, ovulation takes place towards the end of estrus except cattle and buffaloes where it takes place about 10-12 hrs after end of estrus [6]. The duration and intensity of estrus, varies between and within breeds of cattle [7,8]. Estrus in European breeds of dairy cattle is more intense than beef or zebu cattle. Particular estrus sign like reddening of vulva, mounting on herd mate are well correlated with the ovulation time [9]. If behavior sign are lacking or not prominent it is obvious that estrus may pass unnoticed, condition described as silent heat. Silent heat is a common problem in buffaloes. Successful recognition of estrous prior to the actual time of ovulation may augment conception rate in both cattle and buffaloes.? 


\begin{tabular}{|c|c|c|c|c|c|c|}
\hline \multicolumn{2}{|r|}{$\begin{array}{c}7 \pm 5 \text { hrs duration of } \\
\text { standing heat }\end{array}$} & \multicolumn{2}{|c|}{$\begin{array}{l}\text { Sperm transport and } \\
\text { capacitation 6-18 hrs }\end{array}$} & \multicolumn{3}{|c|}{$\begin{array}{l}\text { Fertile life of ovum } \\
\quad<12 \text { hrs }\end{array}$} \\
\hline 0 & 7 & 13 & 23 & 28 & 34 & $40 \mathrm{~h}$ \\
\hline
\end{tabular}

\section{Estrous cycle}

Cow is non seasonal polyestrous animal. The estrous cycle is of, average $21 \pm 3$ days. The different stages are, pro-estrus $\left(18^{\text {th }}\right.$ to $20^{\text {th }}$ day), estrus ( 0 day), met-estrus ( $1^{\text {st }}$ to $5^{\text {th }}$ day) and di-estrus ( $6^{\text {th }}$ to $17^{\text {th }}$ day of cycle) of estrous cycle.

Estrous behavior in cattle: Three distinct patterns are observed during estrus includes male like mounting, rise in spontaneous activity and mating responses. Receptive animal may perhaps be identified in herd by sexual attractiveness and receptivity. The female stands immobile for mounting on her, indicates that she is definitely in heat [10]. Pug mark on back and dirt on flank is also a clear cut indication of animal in heat. Hair on tail head is ruffled or missing due to frequent mounting by herd mates. Standing to be mounted is yet the best sign of heat, although it is displayed only in limited cases. Therefore mounting on herd mate is better option [11]. Secondary behavioral sign observed before real "standing heat" includes frequent urination, separation from herd, chin resting, back rubbing, nervousness, restlessness, walking along fences, bawling, aggression, arching of back, loss of appetite and sudden drop in milk production. Other supportive sign include licking, sniffing, head lift up, lip curling and flehman's reaction (up curling of lips by female or male after touching the genitalia of raged animal). Physical sign of estrus include the tumefaction of vulva, reddening of vulva (bright cherry pink color), excess mucus discharge [12] and tone in uterus. Closeness in animals coming into heat usually congregates and form small groups of three to five animals called sexually active group (SAG). It is easy to detect heat if sexually active group exist in herd. The period of receptivity lasts for 18-24 hrs. A bloody discharge at cessation of behavioral estrus usually indicates a missed heat. A careful monitoring required for such animal with bloody discharge for returning to heat [13].

? The sign of heat is clear cut and prominent when activities like milking and feeding are minimal, i.e. heat detection should be avoided at milking and feeding time. Failure to watch critically for long time is most common cause of poor heat detection.

During copulation the female may display postural alteration to facilitate mating, called sexual presentation. The cow may exhibit an orgasm like reaction, since some females maintains a typical posture for several seconds after copulation. At the time of ejaculation the electrical resistance of skin dropped suddenly.

Estrous behavior in buffalo: Buffaloes are shy or poor breeder. They are seasonally poly estrous; the estrous behaviors are shown during September to January, with a peak during October to November. The onset of the breeding season is associated with a higher intake of energy and a lower intake of protein. Low blood glucose level with high serum urea concentration in summer, associated with sub fertility. Behavioral sign in buffaloes are less obvious than those in cattle; therefore less than one third of buffaloes in heat might be detected by homosexual behavior [14]. Unlike cattle obvious and raged sign in buffaloes are not pronounced. Hetero sexual behavior, particularly standing to be mounted by a bull, is most reliable sign of estrus in buffaloes, where as homosexual behavior observed only occasionally. Sign such as swelling of vulva, clear transparent mucus discharge, spontaneous milk letdown, bellowing, restlessness [15], frequent urination and raised tail vary in intensity from animal to animal, and in relation to standing estrus. Generally in buffaloes, estrus commences towards late evening and the peak sexual activity occurs during hours of darkness. The cases of silent estrus higher in herd using A.I. rather adopting natural service and this may often indicate that the problem may lie with the heat detection rather than animal itself. Copulation in buffaloes lasts for 20-30 seconds. Bio-stimulation favors behavior sign of estrus clearly.

\section{Protocol for successful heat detection: [ 13]}

1. Tracking of individual animal throughout their life using permanent numbering system.

2. A sound record keeping system should be supplemented with frequent information updates.

3. Standard operating procedure (SOP) should be established. Punctual staff should be selected for the heat detection program and recording information like animal identification, time of onset of heat with respect to different sign and estimating ovulation time.

4. Morning hours are crucial for heat detection as heat detection rate were higher during morning hours [16]. Cow in heat is the first cow to rise in morning in herd.

5. Any interruption to cattle such as feeding or milking should be avoided during monitoring.

6. Special surveillance required for detecting animal grouping activity i.e., SAG. Cattle approaching heat usually congregate together.

7. Duration of heat may change with respect floor surface, as activity rises 3-15 times greater on soil surface than on concrete. There is sudden drop in mounting activity on slippery surface.

8. Heat detection aids should be used wisely and 
efficiently. Heat detector should be used only as a supplement to visual observation rather replacement.

9. The herd may synchronize with hormones or its combination to increase the probability of detecting estrus at appropriate time.

10. To catch every in heat a balance programme should be formulated keeping in view that animal return to estrus 18-24 days later.

11. Hoof problems and sore feet should be treated immediately as lame cattle will not mount or permit to ride on, which decreases the chances of detecting animal in heat.

12. Standard protocol should be followed and all activities are documented.

Heat detection efficiency and accuracy: Efficiency and accuracy of heat detection is increased by noticing animal in heat, before elapse of 50 days of parturition. Factors which affect the expression of estrus should be thoroughly monitored. Heat detector like KaMaR or BeaCon can be used. Herd is critically monitored using heat expectancy chart. Number and percentage of breedable heat should be observed carefully. Efficiency of detection is expressed as percentage of possible estrus period that are observed in a given period of time. The accuracy of detection is the percentage of estrous period observed that is true estrus.

Scoring scale for estrous signs: This score card is used to decide whether the animal is in heat or not. Behavioral of estrous sign displayed by animal at 2-3 hours interval, were assigned points as table given below and total points are calculated. If the sum of points during consecutive observation exceeds 100 points, the animals then considered to be in estrus [11].

\begin{tabular}{lc}
\hline Estrous signs & Points \\
\hline Flehmen reaction & 3 \\
Restlessness & 5 \\
Sniffing of vulva of herd mate & 10 \\
Mounting without standing heat & 10 \\
Chin resting on back of herd mates & 15 \\
Mounting attempts on other cow & 35 \\
Mounting attempt from head (front) side & 45 \\
Standing heat & 100 \\
\hline
\end{tabular}

Measurement of intensity of estrus [17]

Score 1: Nervousness and unusual interest in herd mate with thin glary vaginal discharge.

Score 2: Period of intense heat with more vaginal discharge, considerable excitement and mounting of other females.

Score 3: Standing to ridden with or without the symptoms given for score 1 or 2 .

\section{Factors affecting efficiency of estrus cycle and time of ovulation}

Estrus behavior of cattle and buffaloes depends on several factors like;

1. Breeds of animals: An-ovulatory estrus is common in cross bred animals as compared to pure bred.
Duration of estrus in European cattle is more compared to Zebu cattle.

2. Heredity factors: Hereditary factors are very important with respect to estrus, ovulation and fertility of animals.

3. Peri-partum diseases in cows: Peripartum diseases reduce intensity of manifestation of estrus and also reduce fertility in long run.

\section{Environmental factors:}

a. Surroundings temperature: Extreme high or low temperature reduces the estrous activity followed by less conception. In severe hot environment the length of estrous cycle may increased and duration of estrus become shorter. Feed consumption reduces in hostile environment [18, 19]. During the summer there is decrease in thyroid activity of buffalo i.e., decreased thyroxin in blood in due course reduces feed consumption and body metabolism. Decreased feed intake eventually influences estrous behavior and reproductive efficiency.

b.Season: Intensity of the estrus is highest during cold followed by rainy and summer season. Cows show more mounting activity in cold weather than in hot weather. The buffaloes are the seasonally polyestrous; they exhibit a distinct seasonal variation in display of estrus, conception and calving. Estrous cycle varies with exogenous source like fodder availability, as it varies with season.

c. Light: Behavioral symptoms of estrus were seen more frequently during the nocturnal period [20]. There is marked photoperiodicity in estrous behavior. The photoperiodicity can control neuro-endocrine activities of gonad.

5. Parity, age and body weight: Estrus display is more related to weight than age. Age and weight at sexual maturity is important for selection of animal for breeding purpose. The manifestation of estrus sign became clearer as parity increases. Age at maturity in heifer 1.5 to 2 year, weight at maturity is 60 percent of adult body weight and age at first calving is 80 percent of adult body weight.

6. Feeding and body condition: Starvation or low grade feeding of animal for long time increases age at sexual maturity in animals. The manifestation of estrus behavior, estrus detection etc also affected by nutritional status of animals. The nutrition was one of the most important factors for conception [18, 19] in animals. Cattle in poor condition or negative energy balance generally have poor reproductive performance. Deficiency of vitamin and minerals (Vitamin A, E \& Selenium) could be the cause of deterioration in sign and symptoms of estrus [19].

7. Body condition scoring (BCS): The pedometer reading has negative correlation with body condition scores in early lactation [21]. Optimum body condition is required for expression of estrus behavior. BCS 4 is good as compared to 5 in 1-5 scale body condition scoring system. If body condition score was higher, milk yield was lower and chances of uterine infection is 
less [22].

8. Level of production: There is an antagonistic relationship between milk production and reproduction in dairy cattle; however neutral effect was also seen [23].

9. Hormonal balance: Hormonal imbalance related to deficient feeding, management and disease conditions, e.g. Anoestrus, repeat breeding etc. Administration of hormones from outside can maintain the balance.

10. Management standard: Total quality management (TQM) is required for optimum production and reproduction. Estrus detection before milking and feeding gave a lower detection rate as compared to after milking and feeding [20]. High grade management with some interventions favors easy detection of heat.

11. Reproductive tract scoring: Reproductive tract scoring (RTS) is a useful technique for measuring the physiological readiness of replacement heifers for breeding. More the reproductive tract score more is chances of conception in heifers in 1 to 5 score card [24]. Reproductive tract scoring is done with Ultrasonography aided per rectal palpation.

\section{Techniques of heat detection}

Different signs are studied carefully for detection of heat. Heat detection aids are very important tools for efficient reproductive management if used in combination with expert eye. Cows with detector (KaMaR) plus CHALK marking on tail were more efficient than detector alone. Visual observation with tail paint is $98 \%$ efficient as compared to heat watch alone i.e. $91 \%$.

1. Vaginal pH: $\mathrm{pH}$ is good indicator of animal in estrus. The $\mathrm{pH}$ falls from 7.0 to 6.72 one day before estrus which further fall to a level of 6.45 immediately before ovulation.

2. Vaginal smear: The differential staining properties of vaginal smears shows cytoplasmic lipids in vaginal smear and urinary sediments. Smear also shows increase in cornified acidophil cells during estrous period.

3. Measurement of vaginal conductivity using probe: Vaginal resistance varies with stage of cycle. The decrease in electrical resistance or rise in conductivity of the vaginal tissues and discharges during estrus were well reported. Vaginal probe approach also includes intra-vaginal or implantable resistance devices with transponder to send the information directly to computer. Measurement of vaginal conductivity require repeated insertion and repeated measurement can produces inflammation which may affects the reading. Vaginal resistance can vary with site of probe in animal i.e., measurement of resistance in posterior vagina is less reliable than anterior vagina.

4. Fern pattern of cervical mucus discharge: The cervical mucus is collected from cow suspected of heat; it is smeared on slide and dried naturally in air. If fern pattern appears in slide in microscope indicates animal in estrus. This pattern appears 84 hours before estrus and starts declining before ovulation [25]. If fern pattern show more branching, it shows appropriate time for insemination. Viscosity of mucus decreases at the time of estrus i.e., it become very thin liquid.

5. Endometrial biopsy: It shows rise in phosphate activity around estrus.

6. Cervical mucus glucose content: The glucose test is more positive on day of estrus than on the other day.

7. Uterine tone: The maximum tone in uterine horn remains on day of estrus. The conception was directly proportional to the degree of tonicity of uterus [15]. Yet it is one of the most reliable indications, although it requires expert hand for the purpose.

8. Change in parlor behavior: Cow in estrus may be less regular in parlor behavior like entry habits, restless in milking chute, kicking during teat cup fitting and milk yield drop. It requires careful observation and more practical experience with cow in parlor.

9. Milk yield fluctuation: Sudden drop in milk (75\% of its usual yield) on estrus followed by recovery at next milking is good indication of estrus. Such drop in milk is due to concentration of estradiol in blood. So far it is good indicator but it requires milk yield recording.

10. Temperature measurement: The temperature of skin, deep body, vagina and milk is measured as means of detecting estrus in cattle. Radio telemetry based vaginal temperature measurement was also used with reliable result. The ruminal temperature also raised during time of estrus measured by sensor based intra ruminal electronic radio-telemetric bolus [26]. On the other hand estrus detection rates by temperature monitoring rarely exceed $70-80$ percent.

11. Heat expectancy charts: This simple management aids allow heat to be recorded and the time of next heat to be predicted so that cow can be viewed more closely at the time of the next expected heat. Both manual and computer based system are developed which assist in easy detection of heat [27].

12. Tail painting: Tail painting/chalking is easy method of heat detection; it is commonly used in combination with visual observation. Fluorescent paint may be used in night for heat detection with artificial provision of electric lamp. The result is not good in buffaloes due to wallowing activity and false positive reading can occur if smearing occurs from false contact with low tree branches or from lying in free stalls. A detection rate of 94 percent was shown to be possible.

13. Use of Androgenized cow: This cow is just like male for estrus detection. The chin ball device may be fitted on the cow [28]. Such system would be cheap as well as there would be little risk of introducing venereal disease in herd. The efficiency varies from 39 to 74 percent.

14. Chin ball device: The device placed under the chin of the bull, causes paint to be smeared on back of the cow if mounting takes place. It works on the principle of "ball point pen" i.e., if chin is pressed on rump it will mark animal in estrus. A buffalo bull fitted with chin 
ball detects heat efficiently if used at least twice daily. The efficiency of estrus detection is around 50 percent if used once daily.

15. Use of marker animals and bull parading: Teaser animals are used for heat detection, especially in close housing system. Marking device such as chin ball may be fitted to teaser bull for proficient heat detection.

16. Gomer bull: The bulls are altered, so that they cannot make sexual contact with female. If the bull mounts, it shows that the female must be in heat.

17. Bio-stimulation: Presence of male in the vicinity of the females, will improve expression of estrus to be detected. It is used commonly as curative measure for silent heat problems especially in buffalo.

18. Pressure sensitive KaMaR or BeaCon heat detector: It is fitted on sacrum of cow. It shows good result in cattle, Moreover in buffaloes the method is not satisfactory. Wallowing might interferes with the efficiency of heat detection in buffaloes [6]. Such detectors were significantly more efficient than chinball-harnessed steers. The mistake can be made with these aids if they are not utilized in conjunction with heat detection records and good judgment. Proper fixation is also important to avoid loss of device. The efficiency is $80-90$ percent.

19. Electronic heat mount detector: Electronic heat mount detector also known as heat watch system, is a radio-telemetric system that sense the mounting activity. The data recoded is transmitted to a receiver then recorded by computer for subsequent retrieval [29]. A cow declared to be in heat if she shows mounting 3 times within 4 hours. A similar instrument the "mount count" is pressure sensitive estrous detector glued at sacral area of cow. The mount count signals through LED lamp which gives exact time of mounting. The efficiency of this system is around 91 percent.

20. Heat patch with visible colour change: The heat patch applied on tail head with fixing device, after mounting the colour of dye changes.

21. Pedometer and activity meters: The cows in heat are more mobile and walk two to four times as compared to non-estrous animals. Activity meters used at the neck or a leg of cow and they may be read by receiver and pass on to computer for retrieval. Some pedometer emits signal in form of light when cows showed increased activity. Careful observation required to remove high false positive reading. Data of cow activity recoded with the help of pedometer has good correlation with estrus [30]. ALT (activity, lying time and temperature) pedometer is a real time watch used for measuring time interval for activity rise [31]. The lack of acceptance has been due to initial cost and expense of replacing lost device. Efficiency of heat detection is 90 to 96 percent.

22. Video camera and recording using CCTV: This system of recording is unique for round the clock observation and data recording of herd. Using timelapse and fast play back, the estrous activity of the night can be viewed in half an hour. It is applicable in intensive system of housing (close housing), however the range of camera may either miss cows because they are not within view of the camera. This method may not applied in loose house and range system.

23. Electronic odour detector: Principle of the device is based on detection of pheromones related to heat. The pheromones are the natural olfactory signal for bull that cow is in heat. Trained dogs were having the ability to detect estrus odour correctly in approximately 80 percent of estrus cow. Dog can detect estrus by urine and milk, after being trained with vaginal fluid samples [32]. The odour is not emitted by vaginal mucus or urine was also reported.

The BOVINOSE (pheromone based sensor system) for estrus detection. It is based on the principle of detection of sex pheromones that are secreted by the cows, exclusively during estrus. Sex-pheromones are associated with estrus [33]. The pheromones are actually released by the dung of cow in estrus. Pheromones are volatile fatty acids i.e., Acetic acid (AA), Propionic acid (PA) and 1- iodo undecane [34]. The synthetic compounds (volatile fatty acids) were rubbed on to dummy cows, and bulls has shown similar response, however only two volatile chemical i.e., AA and PA isolated later in faeces estrous cow [33]. It is up to 90 percent efficient. Still the project is running in future if successful, further development steps are anticipated.

24. Milk progesterone Detection: Cattle and buffalo can be bred on the day of lowest progesterone $\left(\mathrm{P}_{4}\right)$ to achieve adequate fertility [35]. The C.L. (corpus luteum) on ovary is source of $\mathrm{P}_{4}$ in milk. As the C.L. lacks the enzymes to convert $\mathrm{P}_{4}$ into other steroids. Therefore it diffuses to the plasma and milk. The $\mathrm{P}_{4}$ level in milk is four to five times higher than in plasma. Yet it is not a practical procedure for large numbers of cows if it is conducted manually. This may offers a potential future method of estrus detection using automatic Kit based system. Developing a programmed/automatic biosensor that includes the ELISA as transduction mechanism. So far it involve a high cost, but this system capable of checking progesterone at every milking, could be extremely valuable for progesterone profiling as well as estrus detection in cows or buffaloes.

25. Heat detection by $17 \beta$-estradiol and $P_{4}$ in milk: Enzyme immune assay (EIA) based determination of pre-ovulatory estradiol in raw milk sample is precise method to describe cows in heat along with $\mathrm{P}_{4}$ isolation and quantification [36]. It is reliable, rapid, economic and a precise method to describe cow heat.

26. Infra red spectroscopy and magnetic resonance spectra: Infrared spectroscopy and nuclear magnetic resonance spectra are carried out to detect estrus related change (inflammatory reaction) in vaginal mucus, vulva and vestibule.

27. Synchronization of estrus: It is one of the important methods for easy detection of heat and timed 
A.I. Synchronization of heat is a process by which group of animal are managed in such a way that they will come in heat on same day. As estrus is controlled and harmonized on a particular day. Different protocols are used for estrus synchronization like ovsynch [37, 38], pre synch, co-synch, select synch, double synch and heat synch $[39,40]$ in both cattle and buffaloes. By manipulating the level of endogenous estrogen preovulatory estrus behavior expressed optimally. Use of estradiol benzoate with or without inclusion of equine chorionic gonadotropin in cow [41]. This method is highly efficient for both cyclic and non cyclic animals; however it require expert supervision for good result.

28. Laparoscopic technique: It is used for study genital organs in general and ovary in particular. Although the technique used for heat detection timely and accurately, it is not economical to be used by farmers in field condition.

29. Use of ultra-sonography for monitoring of ovarian status: Monitoring the ovarian function with the help of ultrasound in bovine has improved the knowledge and understanding of follicular dynamics and number of developing follicles. Ultra songraphy can also be used to detect ovulation time with respect to different sign of heat [9]. An-ovulation is also diagnosed by ultrasonography [19]. Measurement of endometrial thickness before and during estrus indicates conception and fertility status [42]. Ultrasonography accurately guides the estrus detection and ovulation time in cow but it require expert person to understand the scan image and instrument needs careful handling and maintenance. The efficiency of ultrasonography is around 85 to 95 percent.

30. Improving estrus detection rate using sensor based fuzzy logic system: Fuzzy function can be used for automatic detection of estrus using fuzzy logic. For input data the system uses previous estrus cases information with data of pedometer for rise in activities. The outputs were organized in three categories: i.e. "in estrus", "may be in estrus" and "not in estrus". The sensitivity was found around ninety percent [43]. Heat can be detected by vaginal fluids using specific sensor [44]. This method focuses on solving the problems rather than modeling the system mathematically, however it requires a sufficient expert knowledge for formulation of rule base, fuzzification and defuzzification. The sensitivity is found 84.2 percent, indicating that the system may improve automatic estrus detection.

1. Use of "Nanotechnology" for motion sensing: Assist in the detection of raised physical activity in cow. The activity data is collected every hour for the cows. The data were analyzed using nanotechnology based intelligence, the soft wares then filters the data against usual activity of herd mate to recognize the cows in estrus and ready to breed. The system is compatible with ear tag identification system, e.g. "Select detect technologies" and "Moo monitor system" device. The message for estrus alert may be received on mobile phone. This method of heat detection is recent updated and advance except the cost of initial investment is high. Accuracy of the system is more than 82 percent.

\section{Advantages of heat detection aid/ heat detector}

It identifies more cow in heat. Greater accuracy of detection means fewer wasted insemination, saving time and keep away from 21 day of loss in production. The technology is easy to use, cost effective and easy to interpret. It improves the submission rate and more accurate timing of A. I., which ultimately increases the profit. Detector can identifies cows even with short heat and cow that sows sign in night. It also works well for differentiating the stages of estrus like pre-estrus, estrus and return to normal however it work well with visual observation rather alone. Thus we can say that the combination of techniques of heat detection should be used to increase heat detection efficiency to 100 percent.

\section{Conclusion}

Inadequate heat detection is one of the major factor limiting reproductive performances in herds; therefore it is an area of farm activity where increased effort or investment is likely to be profitable. Cattle come into estrus at all times of the day, moreover she may not be very active in hot weather and remain in heat for only a short period of time (roughly 12-18 hours), making it difficult to observe. Allowing animal to interact in small group (three to five) with two to three visual observations per day will increase the chances of catching cycling animals. The use of synchronization and heat-detection aids can greatly shorten the time spent in heat detection but will not benefit a non- cycling herd. The management interventions are required to maintain the herd cyclic. For this high grade nutrition should be provided, and also need exceptional cow comfort including hoof health, body condition and non slippery surface.

\section{References}

1. Roelofs, J., Lopez-Gatius, F., Hunter, R. H. F., Van Eerdenburg, F. J. C. M. and Hanzen, C. (2010) When is a cow in estrus? Clinical and practical aspects. Theriogenology 74 (3). 327-344.

2. Karir, T., Nagvekar, U. H., Samuel, G., Sivaprasad, P., Chaudhuri, P. and Samad, A. (2006) Estimation of progesterone in buffalo milk by radioimmunoassay. Journal of Radioanalytical and Nuclear Chemistry. 267 (2): 321325.

3. Heape, W. (1900) The "sexual season" of mammals and the relation of the "prooestrum" to menstruation. $Q J$ Microsc Sci. 44:1-7.

4. Roberts, S. J. (2001) Veterinary Obstetrics and Genital diseases, 2nd Ed., CBS Publisher \& Distributors, New Delhi.

5. Sjaastad, O. V., Hove, K. and Sand, O. (2003) Reproduction. In: Physiology of Domestic Animals. First edition. Scandinavian Veterinary Press, Oslo, Norway. Chapter 18.

6. Noakes, D. E., Parkinson, T. J., England, G. C. W. and Arthur, G. H. (2001) Arthur's Veterinary Reproduction and obstetrics,8th Ed., Harcourt Publishers Limited Pennsylvania. 
7. Walker, S. L., Smith, R. F., Routly, J. E., Jones, D. N., Morris, M. J. and Dobson, H. (2008) Lameness activity time-budget and estrus expression in dairy cattle. J.Dairy Sci. 91,4552-4559.

8. Venkat Naidu, G. and Rao, K. B. (2006) Estrus pattern and conception rate in post partum lactating Ongole (Zebu) cows. Indian J. Anim. Reprod. 27(1), 14-17.

9. Layek, S. S., Mohanty, T. K., Kumaresan, A., Behera, K. and Chand, S. (2011) Behavioural signs of estrus and their relationship to time of ovulation in Zebu (Sahiwal) cattle. Animal Reproduction Science. 129, 140-145.

10. Negussie, F., Kassa, T. and Tibbo, M. (2002) Behavioural and physical sign associated with estrus and some aspect of reproductive performance in Fogera cows and heifers. Trop. Anim. Health Prod. 34, 319-328.

11. Roelofs, J. B., Van Eerdenburg, F. J. C. M., Soede, N. M. and Kemp, B. (2005) Various behavioural signs of estrus and their relationship with time of ovulation in dairy cattle. Theriogenology. 63: 1366-1377.

12. Yoshida, C. and Nakao, T. (2005) Some Characteristics of Primary and Secondary Oestrous Signs in High-producing Dairy Cows.Reproduction in domestic animals. 40: 150-155.

13. Du Ponte, M. W. (2007) The Basics of Heat (Estrus) Detection in cattle. LM-15 series, Co-operative extension service, University of Hawai' Manoa.

14. Suthar V. S. and Dhami, A. J. (2010) Estrus detection methods in buffalo. Vet. World, 3 (2):94-96.

15. Gunasekaran, M., Singh, Charan. and Gupta, A. K. (2007) Effect of Oestrus Behaviour on Fertility in Murrah Buffaloes. Indian Journal of Dairy Science 60 (5): 348-351.

16. Dransfield, M. B., Nebel, R. L., Pearson, R. E. and Warnick, L. D. (1998) Timing of insemination for dairy cows identified in estrus by a radiotelemetric estrus detection system. J. Dairy Sci. 81(7): 1874-1882.

17. Van Eerdenburg, F. J. C. M., Karthaus, D., Taverne, M. A. M., Merics, I. and Szenci, O. (2002) The relationship between estrous behavioral score and time of ovulation in Dairy cattle. J. Dairy Sci. 85, 1150-1156.

18. Walsh, R. B., Kelton, D. F., Leslie, K. E., Walton, J. S. and Leblanc, S. J. (2007) Prevalence and risk factors for post partum anovulatory condition in Dairy Cows. J. Dairy Sci. 90,315-324.

19. Zobel, R., Pipal, I. and Buic, V. (2012) Anovulatory estrus in dairy cows: treatment options and season on its incidence. VeterinarskiArchiv. 82 (3): 239-249.

20. Van Vliet, J. H. and Van Eerdenburg, F. J. C. M. (1996) Sexual activities and oestrus detection in lactating Holstein Cows. Applied Animal Behaviour Science. 50, 57-69.

21. Levendah, P. and Chagunda, M. G. G. (2010) On the use of physical activity monitoring for estrus detection in dairy cows. Journal of Dairy Science. 93(1):249-259.

22. Aungier, S. P. M., Ronche, J. F., Sheehy, M. and Crowe, M. A. (2012) Effect of management and health on the use of activity monitoring for estrus detection in dairy cows. Journal of Dairy Science. 95 (5): 2452-2466.

23. Grohn, Y. T. and P. J. Rajala-Schultz. (2000) Epidemiology of reproductive performance in dairy cows. Anim. Reprod. Sci. 60-61: 605-614.

24. Anderson, K. J., Lefever, D. G., Brinks, J. S. and Odde, K. G. (1991) The use of reproductive tract scoring in beef heifers. Agri-Practice. 12: 19-26.

25. Mangal, V. (2009) Study on Estrous Behaviour, Cervical Mucus Characteristics and Fertility in Sahwal Cattle . M. V.Sc. Thesis. NDRI, Karnal, Haryana, India.

26. Boehmer, B. H. (2012) Ruminal temperature for identification and prediction of estrus in beef cows. M. Sc. Thesis, Okhlahoma State University.

27. Burke, C. R., Davis, K. L. and Jago, J. G. (2005) Predicting next oestrus date and drafting automatically milked cows for focused attention on oestrus detection. Proceedings of the New Zealand Society of Animal Production. 65, 231-5.

28. Gwazdauskas, F. C., Nebel, R. L., Sprecher, D. J., Whhittier, W. D. and Mc Gilliard, M. L. (1990) Effectiveness of rump- mounted device and androgenized female for detection of estrus in dairy cattle. Journal of Dairy Science. 73, 29652970.

29. At Taras, E. E. and Spahr, S. L. (2001) Detection and characterization of estrus in dairy cattle with an electronic heat mount detector and electronic activity tag. Journal of Dairy Science. 84 (4): 792-798.

30. Lopez-Gatius, F., Santolaria, P., Munder, I. and Yaniz, J. L. (2005) Walking activity at estrus and subsequent fertility in dairy cows. Theriogenology. 63: 1419-1429.

31. Brehme, U., Stollberh, U., Holz, R. and Schleusenner, T. (2008) ALT pedometer- New sensor aided measurement system for improvement in oestrus detection. Computers and Electronics in Agriculture 62 (1): 73-80.

32. Fischer-Tenhagen, C., Wetterholm, L., Tenhagen, B. and Heuwieser, W. (2011) Training dogs on a scent platform for oestrus detection in cows. Applied animal Behaviour Science. 131 (1-2):63-70.

33. Weigerinck, W., Setkus, A., Buda, V., Borg-Karlson, A. K., Mozuraitis, R. and de Gee, A. (2011) BOVINOSE: Pheromone-Based Sensor System for Detecting Estrus in Dairy Cows. Procedia Computer Science. 7: 340-342.

34. Sankar, R. and Archunan, G. (2008) Identification of putative pheromones in bovine (Bos taurus) faeces in relation to estrus detection. Animal Reproduction Science. $103(1-2)$ 149-153.

35. Samad, H. A., Ahmad, N., Bengmen and Rehman, N. U. (2004) Use of milk progesterone Assay for Monitoring Oestrus and Early Pregnancy in Nili-Ravi Buffaloes. Pakistan Veterinary Journal. 24 (3): 121-124.

36. Domenech, A., Pich, S., Aris, A., Plasencia, C., Bach, A. and Serrano, A. (2011) Heat identification by $17 \beta$-estradiol and progesterone quantification in individual raw milk sample by enzyme immunoassay. Electronic Journal of Biotechnology. 14(4).

37. Bridges, G. A., Helser, L. A., Grum, D. E., Mussard, M. L. and Day, M. L. (2008) Decreasing the interval between GnRH and PGF2 $\alpha$ from 7 to 5 days and lenegenthening proestrus increases timed- AI pregnancy rate in beef cows. Theriogenology. 69: 843-51.

38. Suadsong, S. (2011) Control of Oestrus and Ovulation in Cows. Vet Med Suppl. 41: 95-98.

39. Mohan, K., Sarkar, M. and Prakash, B. S. (2009) Efficiency of Heatsynch protocol in estrous synchronization, ovulation and conception of Dairy buffaloes (Bubalus bubalis). Asian Australian. J. Anim. Sci. 22(6): 774-780.

40. Mohan, K. and Prakash, B. S. (2010) Changes in endogenous and expression of behaviours associated with estrus during the preovulatory period in Heat synch treated Murrah buffaloes (Bubalus bubalis). Tropical Animal Health and Production. 42 (5): 947-952.

41. Bryan, M. A., Emslie, R., Heuer, C. (2008) Comparative efficacy of an 8 day cue-Mate/ estradiol benzoate program with or without inclusion of equine chorion gonadotropin in anestrus dairy cows. Reprod. Fertil Dev. 20: 85.

42. Souza, A. H., Silva, E. P. B., Cunha, A. P., Gumen, A., Ayres, H., Brusveen, D. J., Guenthen, J. N. and Wiltbank, M. C. (2011) Ultrasonographic evaluation of endometrial thickness near timed A.I. as predictor of fertility in high producing dairy Cows. Theriogenology 75: 722-733.

43. Brunassi, L. A., de Moura, J. D., Naas, I. A., do Vale, M. M., de Souza, R. L., de Lima, K. A. O., de Carvalho, T. M. R. and de Freitas Bueno, L. G. (2010) Improving detection of dairy cow estrus using fuzzy logic. Sci. Agric. (Piracicaba, Braz.). 67(5): 503-509.

44. Borecki, M., Kozicki, M., Scmidt, J., Krowin-Pawlowski, M. L., Szmidt, M. and Umbanska, K. (2012) Sensing of Functional state of Fertility of cows. Sensor devices: The Third International Conference on Sensor Device Technologies and Application pp. 14-20.

$* * * * * * * *$ 